\title{
Singular value decomposition (SVD) for extraction of gravity anomaly associated with gold mineralization in Tongshi gold field, Western Shandong Uplifted Block, Eastern China
}

\author{
B. B. Zhao and Y. Q. Chen \\ School of Earth and Mineral Resource, China University of Geosciences, Beijing 100083, China
}

Received: 7 June 2010 - Revised: 28 November 2010 - Accepted: 9 December 2010 - Published: 15 February 2011

\begin{abstract}
A singular value decomposition (SVD) program on MATLAB platform was effectively used to handle gravity signals for the Tongshi gold field. Firstly, the gravity signals were decomposed into different eigenimages with the help of singular value decomposition method (SVD). Secondly, the thresholds between the eigenvalues reflecting different layers of ore-controlling factors were established by multi-fractal method. Finally images reflecting different layers of orecontrolling factors were rebuilt. This yielded two layers of two-dimensional singular value images that depict regional and local ore-controlling factors, respectively.
\end{abstract}

1. The regional ore-controlling factor is a saddle valley with the gravity anomaly values varying from -55 to $51 \mu \mathrm{m} \mathrm{s}^{-2}$ on the NW trending swell with the gravity anomaly values varying from -55 to $567 \mu \mathrm{m} \mathrm{s}^{-2}$ on the SW side of the Mesozoic volcanic sedimentary basin with the gravity anomaly values varying from -56 to $-974 \mu \mathrm{m} \mathrm{s}^{-2}$. The saddle valley might be tectonically an extensional area where the Tongshi complex pluton and all gold deposits are located and thus this area is favorable for gold deposits.

2. The local ore-controlling factor is the Tongshi complex pluton with a negative circular gravity anomaly varying from -339 to $-11 \mu \mathrm{m} \mathrm{s}^{-2}$ and the ring contact metasomatic mineralization zone around the Tongshi complex with the positive gravity anomaly varying from 37 to $345 \mu \mathrm{m} \mathrm{s}^{-2}$. The skarn and porphyry types of gold deposits are located within the complex pluton and the Carlin and cryptobreccia types of gold deposits are

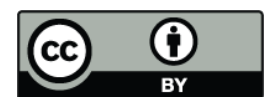

Correspondence to: Y. Q. Chen (yqchen@cugb.edu.cn) located within the contact metasomatic mineralization zone. Thus both of them are potential areas for gold deposits.

3. The Tongshi gold field exhibits a typical complexity with multi-layers of ore-controlling factors.

\section{Introduction}

Singularity is a property of different types of nonlinear natural processes, including cloud formation, rainfall, hurricanes, flooding, landslides, earthquakes, wildfires and mineralization (Cheng, 2008). In nonlinear theory, oreforming process is a kind of singular geological process. The singularity may result in anomalous amount of energy release or material accumulation within a narrow spatialtemporal interval. The results of singular geological process, for example, mineral deposits and ore-forming anomalies, represent fractal or multi-fractal distribution which can be described with power-law function (Cheng, 2009). How to separate the information associated with ore-forming process from whole complicated geological process is a subject we explore.

With the SVD, a matrix $\mathbf{X}$ can be decomposed to a series of eigenimages. The SVD can be used for signal and noise separation (Glifford, 2005; Vrabie et al., 2004). Ulrych et al. (1988) illustrated the application of SVD to seismic profiles. Freire and Ulrych (1988) used SVD to separate the downgoing and upgoing waves in vertical seismic profiling (VSP). Cagnoli and Ulrych (2001) evaluated the amount of wavy reflections in ground-penetrating radar (GPR) image of base surge deposits. The eigenvalues derived by means of

Published by Copernicus Publications on behalf of the European Geosciences Union and the American Geophysical Union. 
SVD represent fractal or multi-fractal distribution described with power-law function. Li (2005) used the multi-fractal SVD for feature extraction and anomaly identification for mineral exploration.

Anomalous amount of energy release or material accumulation which the singular geological process may result in within a narrow spatial-temporal interval might exist in some specific eigenimages. The energy of eigenimages or the squared eigenvalue $(\lambda)$ perhaps represents multifractal distribution, and can be described with the power-low functions. Thus some eigenimages which can be separated and extracted may characterize some anomaly information associated with mineralization.

In this paper, the SVD and multifractal methods are used for analyzing the gravity data surveyed at scale of 1:50000 within Tongshi gold field, Western Shandong Uplifted Block, Eastern China. We try to reveal the spatial relationship between the deep geological structure and gold mineralization in Tongshi gold field by extracting the gravitational information in certain frequency to provide valuable evidences for predicting new gold deposits in depth.

\section{Singular value decomposition (SVD)}

The SVD is a factorization of a rectangular matrix $\mathbf{X}$ into orthogonal matrices, i.e.

$\mathbf{X}=\mathbf{U S V}^{T}$

Where $\mathbf{U}$ is a left eigenvector matrix, $\mathbf{S}$ is a diagonal matrix called singular value matrix and $\mathbf{V}^{T}$ is a right eigenvector matrix. The singular values of $\mathbf{X}$ are the positive entries of $\mathbf{S}$ which can be entered in decreasing order along its main diagonal and are equal to positive square roots of the eigenvalues $\left(\lambda_{i}\right)$ of the covariance matrices $\mathbf{X} \mathbf{X}^{T}$ and $\mathbf{X}^{T} \mathbf{X}$. Thus

$\mathbf{S}=\operatorname{diag}\left(\sigma_{1}, \sigma_{2}, \ldots, \sigma_{r}\right)$

where $r=\operatorname{rank}(A), \sigma_{1} \geq \sigma_{2} \geq \ldots \geq \sigma_{r}, \sigma_{i}=\sqrt{\lambda_{i}}$.

The singular value decomposition of $\mathbf{X}$ can be also written as follows:

$\mathbf{X}=\sum_{i=1}^{r} \sigma_{i} u_{i} v_{i}^{T}$

where $r$ is the rank of $\mathbf{X}, \mathbf{u}_{i}$ is the $i$-th eigenvector of $\mathbf{X} \mathbf{X}^{T}$, $v_{i}$ is the $i$-th eigenvector of $\mathbf{X}^{T} \mathbf{X}, \sigma_{i}$ is the $i$-th singular value of $\mathbf{X}$, and $\mathbf{u}_{i} \mathbf{v}_{i}^{T}$ is an $m \times n$ matrix of unitary rank called the $i$-th eigenimage of $\mathbf{X}$ (e.g. the first eigenimage, $\sigma_{1} \mathbf{u}_{1} \mathbf{v}_{1}^{T}$. According to Eq. (3), the original matrix can be rebuilt with all of the eigenimages. Also if some specific eigenimags are selected, a sub-matrix can be reconstructed.

The singular values obtained by SVD method have features as follows: (1) they are distributed in decreasing order along main diagonal; (2) they represent different weighting coefficients of eigenimages; (3) their squared values (i.e. $\lambda$ ) are equivalent to power spectral density values in Fourier space ( $\mathrm{Li}, 2005)$.

Relatively few eigenimages contain the most energy of matrix $\mathbf{X}$. The percentage of each eigenimage $\left(P_{i}\right)$ can be calculated as the following equation (Freire and Ulrych, 1988; Li, 2005):

$$
P_{i}=\frac{\sigma_{i}^{2}}{\sum_{j=1}^{r} \sigma_{j}^{2}}=\frac{\lambda_{i}}{\sum_{j=1}^{r} \lambda_{j}}
$$

\section{Application}

Geophysical fields are very useful in inferring deep-seated geological structures and delineating concealed geological objects such as buried intrusive bodies and ore bodies. Effective use of gravity fields, like other geophysical fields, depends on establishment of a set of signatures that characterize forms, sizes and depths, as well as masses of various geological objects and their relationship to mineralization (Pan and Harris, 2000). The most direct information acquired from gravity fields is the density of geological bodies. A high gravity value indicates the presence of geological objects with higher average density than the materials surrounding them. Conversely, a low gravity value indicates the presence of geological bodies with relatively low average density.

Because of heterogeneity in the density of geological bodies created during complicated geological processes, even the same lithological unit in different spatial locations can cause different gravity anomalies, whereas different lithological units can produce similar gravity fields. This non-unique correspondence can cause some difficulties in inferring deep-seated geological structures and in delineating concealed geological objects. Thus, intrinsic geological and geochemical information is required.

The scale of gravity anomalies is related not only to the size, but also to the depth of geological bodies. The same scale and type of anomaly might be produced by different lithological units located at different depths. Different scales and types of anomalies are possibly associated with differences in both the lithology and buried depth of geological bodies. These complexities and difficulties mean that new information decomposition techniques are required to identify possible ore-bearing locations from huge amounts of geosciences data.

\subsection{Mineralization characteristics in Tongshi gold field}

The Tongshi gold field is located at the concealed basement area in the southwestern margin of the Mesozoic Pingyi volcanic sedimentary basin in Western Shandong Uplifted 


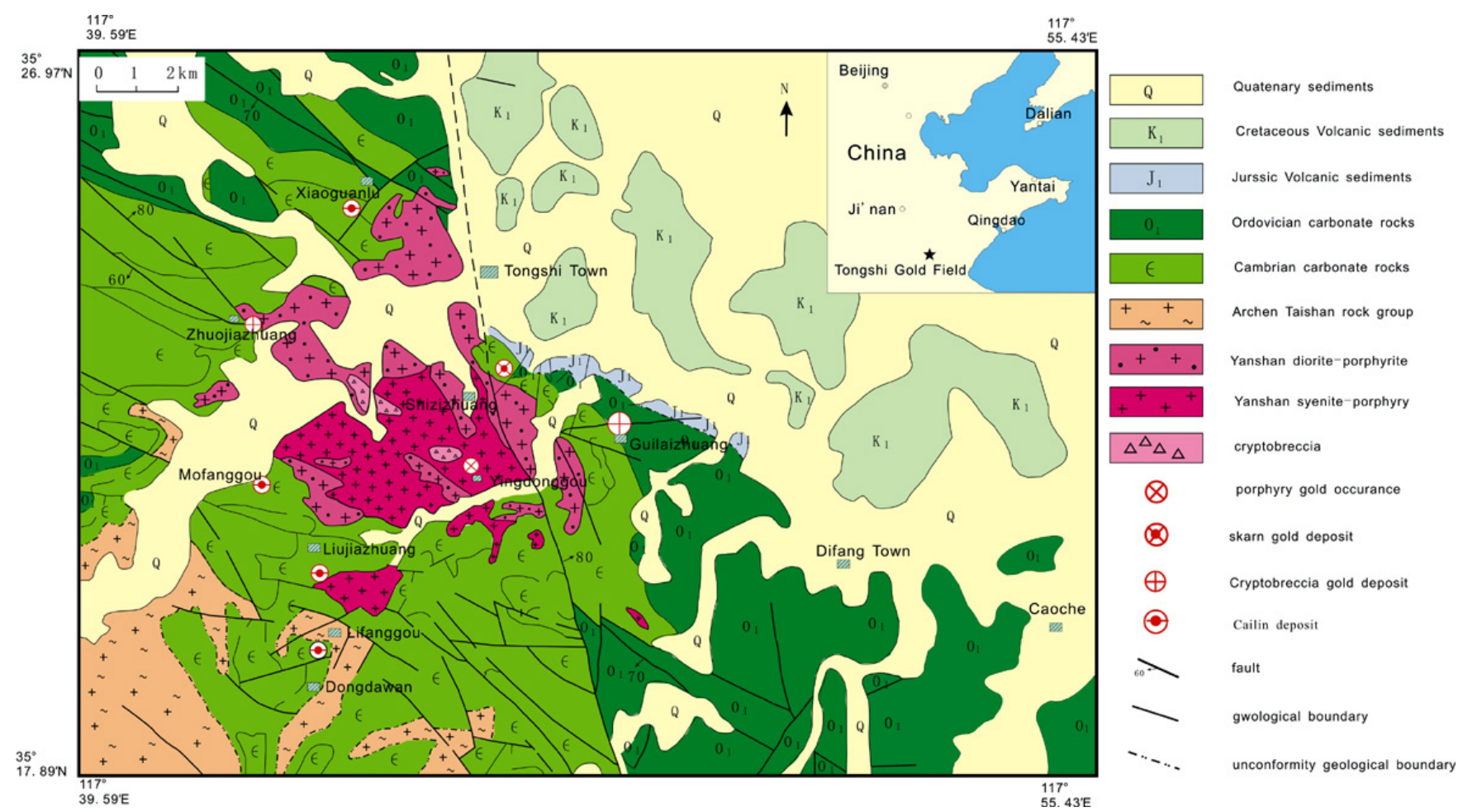

Fig. 1. Geology and mineralization of the Tongshi gold field, Western Shangdong Uplift Block, Eastern China (revised after Chen et al., 2000).

Block, Eastern China (Chen et al., 2001a, b). The concealed basement area where the Cambrian-Ordovician carbonates lay on the Archean green stone was intruded by the Tongshi subvolcanic alkalic intrusive complex which consists of syenite porphyries and diorite porphyrites. The $w\left({ }^{40} \mathrm{Ar}\right) / w\left({ }^{39} \mathrm{Ar}\right)$ analysis of amphiboles from the diorite porphyrite and the syenite porphyry suites have recorded ages of 188.4 Ma and 189.8 Ma (Lin and Tan, 1996). The zircon SHRIMP U-Pb ages vary from $167.9 \mathrm{Ma}$ to $183 \mathrm{Ma}$ (Hu et al., 2005). The mineralization has the zonation with the center of the Tongshi complex: porphyry gold occurrences are located within the intrusive complex. Skarn iron-copper-gold occurrences are located at the inner contact metasomatic zone between the intrusive complex and its host rocks. Farther from the center, Crypto-breccia and Carlin gold deposits can be found. The large Guilaizhuang gold deposit has double mineralized features of both Cryptobreccia and Carlin types (Fig. 1) (Chen et al., 2000; Zhu et al., 2000; Yu, 2001).

\subsection{Extraction of gravity anomaly information}

The gravity data surveyed at grid of $500 \mathrm{~m} \times 250 \mathrm{~m}$ for this study is provided by Yanzhou Geology and Mineral Exploration Institute of Shandong province. The resolution of surveyed data is $\pm 232 \times 10^{-2} \mu \mathrm{m} \mathrm{s}^{-2}$. The control area is $408 \mathrm{~km}^{2}$. The densities of the exposed geological bodies vary in decreasing sequence: $2.73 \sim 2.90 \mathrm{~g} \mathrm{~cm}^{-3}$ for the Archean greenstone belt), $2.64 \sim 2.76 \mathrm{~g} \mathrm{~cm}^{-3}$ for the Cambrian-Ordovician carbonates, $2.61 \sim 2.71 \mathrm{~g} \mathrm{~cm}^{-3}$ for the Tongshi intrusive complex, $2.46 \sim 2.53 \mathrm{~g} \mathrm{~cm}^{-3}$ for the Jurassic-Cretaceous volcanic sedimentary rocks (Wang et al., 2003).

The SVD is used for analyzing the gravity data surveyed at scale of 1:50000 within Tongshi gold field, Western Shandong Uplifted Block, Eastern China (Fig. 2).

Freire and Ulrych (1988) defined band-pass $\mathbf{X}_{\mathrm{BP}}$, low-pass $\mathbf{X}_{\mathrm{LP}}$, and high-pass $\mathbf{X}_{\mathrm{HP}}$ SVD images in terms of the ranges of singular value used.

$$
\begin{aligned}
& \mathbf{X}_{\mathrm{LP}}=\sum_{i=1}^{p-1} \sigma_{i} \mathbf{u}_{i} \mathbf{v}_{i}^{T} \\
& \mathbf{X}_{\mathrm{BP}}=\sum_{i=p}^{q-1} \sigma_{i} \mathbf{u}_{i} \mathbf{v}_{i}^{T} \\
& \mathbf{X}_{\mathrm{HP}}=\sum_{i=q}^{r} \sigma_{i} \mathbf{u}_{i} \mathbf{v}_{i}^{T}
\end{aligned}
$$

where $p$ and $q$ are eigenimage indexes of breakpoints. The choices of $p$ and $q$ depend on the magnitudes of the singular values themselves. One of the unique properties of singular geological processes is that their end products 


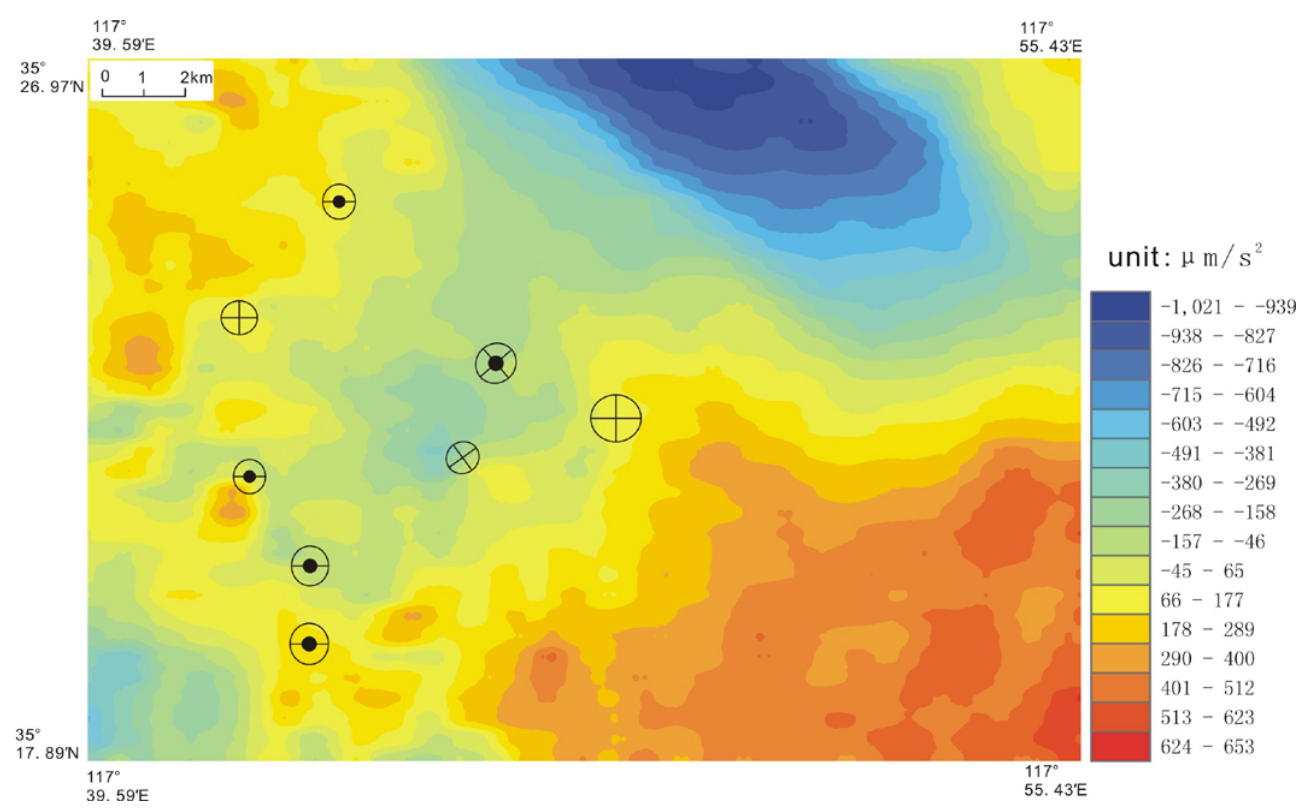

Fig. 2. The original gravity data image surveyed at scale 1:50 000. The legends for the gold deposits see in Fig. 1.

obey the power-law distribution. For example, gradetonnage of mineral deposits, and number-size distribution of mineral deposits follow power-law distribution (Turcotte, 1997; Cheng, 2008; Hronsky and Groves, 2008). Here we will use the power-law distribution to determine $p$ and $q$.

The main proposition supporting the non-linear theory and application of power-law models is that mineralization can result from some singular geological processes, and that mineral deposits can regarded as the products of some singular geological processes, and that these singular geological processes may be characterized by power-law models (Cheng, 2007, 2009). The square of the singular values (i.e. $\lambda$ ) corresponds to the spectral energy densities of eigenimages ( $\mathrm{Li}, 2005)$. Thus, the sum of energy (i.e. a measurement of energy in spectral energy radius or scale) whose squared singular values are larger than $\lambda_{i}$ can be written as follows (Li and Cheng, 2004):

$E\left(\lambda \mid \lambda \geq \lambda_{i}\right)=\sum_{k=1}^{i} \lambda_{k}$

And its relevant proportion $(P)$ is:

$P\left(\lambda \mid \lambda \geq \lambda_{i}\right)=\sum_{k=1}^{i} \lambda_{k} / \sum_{t=1}^{r} \lambda_{t}$.

$\lambda$ and $E$ (or $P$ ) may represent a fractal or multifractal $(\mathrm{Li}$, 2005; Li and Cheng, 2004; Li and Liu, 2003).

$E \propto \lambda^{\alpha}$

or

$P\left(\lambda \mid \lambda \geq \lambda_{i}\right) \propto \lambda^{\alpha}$.

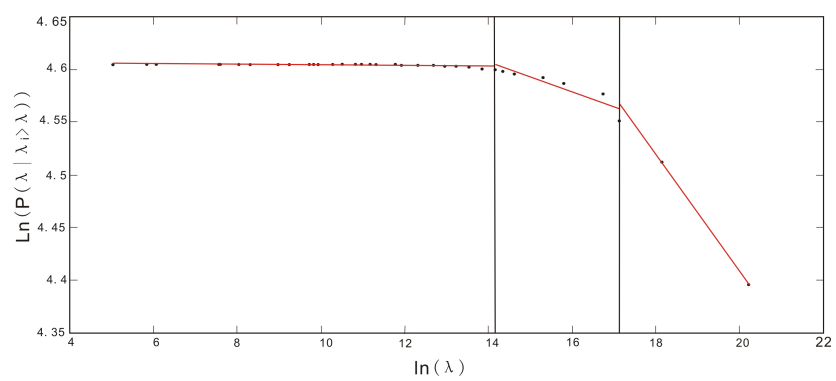

Fig. 3. $\log$ - $\log$ plot of $\lambda-P$ with two break points, $\ln \left(\lambda_{p}\right)=17.13$, $\ln \left(\lambda_{q}\right)=14.17$.

Because of the power law distribution, the curve in log$\log$ plot of $\lambda-P$ can be separated into several segments due to different slopes. And the break points are $p$ and $q$ (sometimes can be separated into more than 3 segments). The reconstruction of some specific eigenimages may reflect some specific geological processes, including ore-forming processes.

With the multi-fractal SVD method, $p$ and $q$ in Eqs. (5), (6), and (7) can be determined. The curve in log-log plot of $\lambda-P$ of gravity signal in Tongshi gold field can be separated into three segments according to the break points between straight lines with different slopes (Fig. 3). The right segment is made of $\lambda_{1}$ and $\lambda_{2}$, and the percentage of its energy is about $90 \%$ of total energy. The reconstructed gravity image with the sum of the 1st and 2nd eigenimages (Fig. 4) usually reflects regional ore-controlling factors.The middle segment is made of ranking from $\lambda_{3}$ to $\lambda_{8}$, and the percentage of its energy is about $9 \%$ of total energy. The reconstructed 


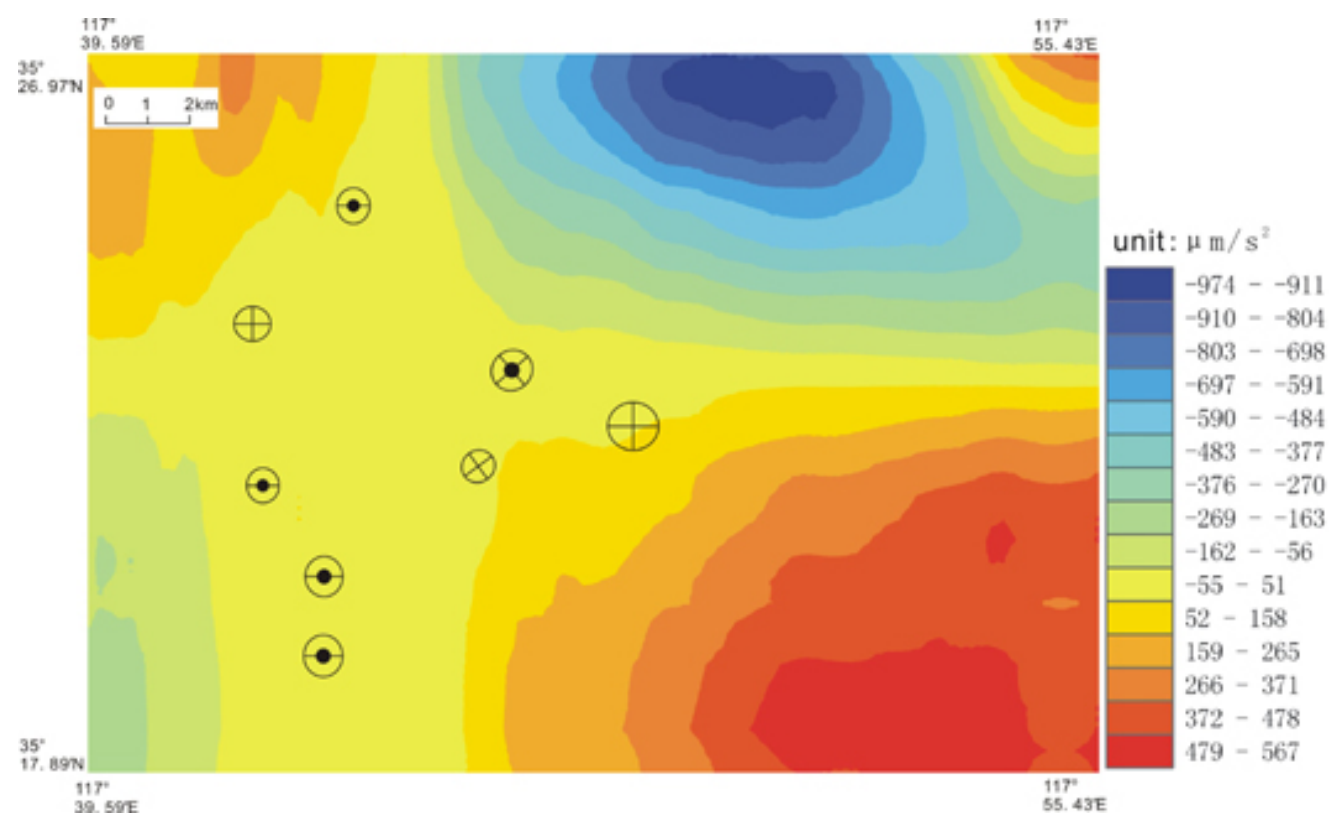

Fig. 4. Reconstructed Image of the 1st and 2nd eigenimages. The legends for the gold deposits see in Fig. 1.

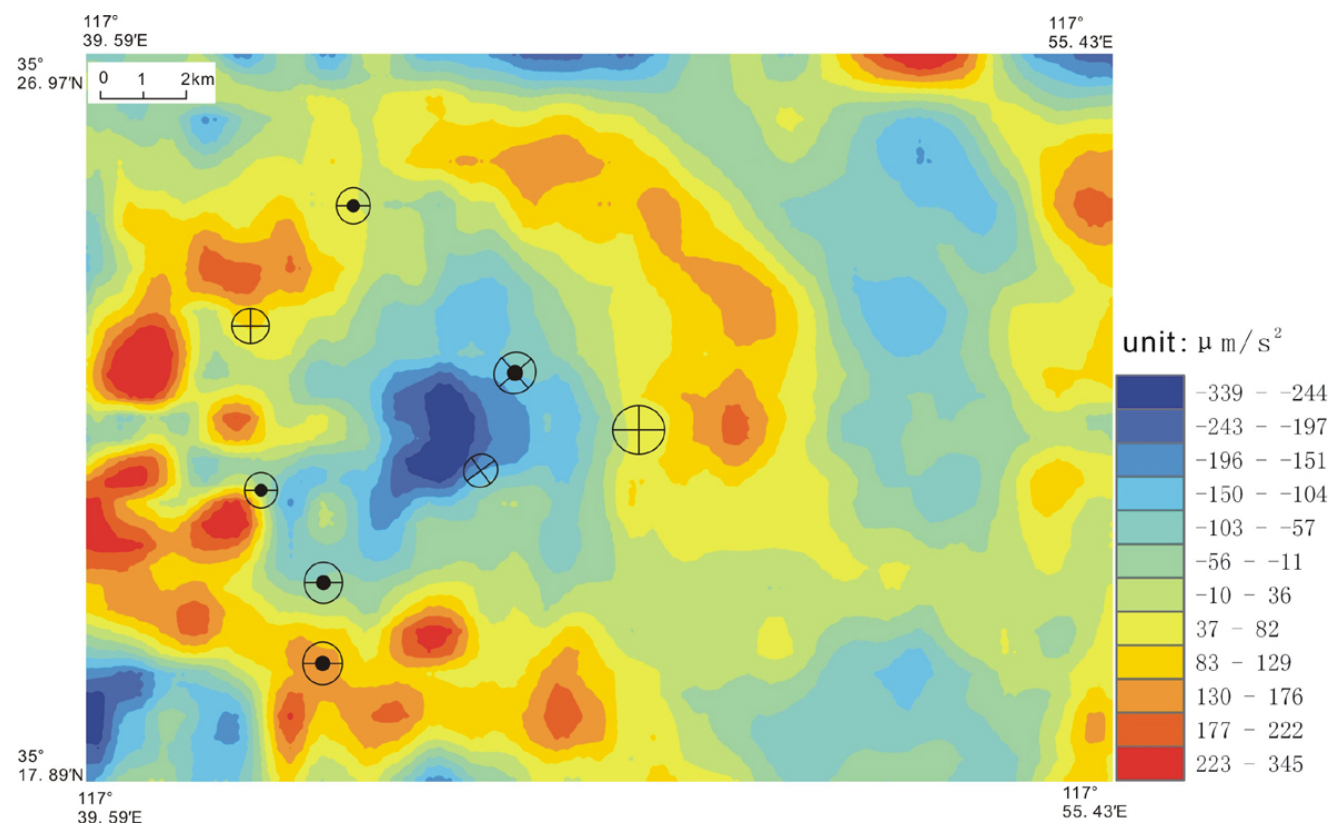

Fig. 5. Reconstructed image from the 3rd to 8th eigenimages. The legends for the gold deposits see in Fig. 1.

gravity image with the sum from 3rd to 8th eigenimages (Fig. 5) usually reflects local ore-controlling factors. The left segment is made of ranking from $\lambda_{9}$ to $\lambda_{35}$, and the percentage of its energy is only about $1 \%$ of total energy. The contents shown by this reconstructed gravity image with the sum from 9rd to 35th eigenimages is generally uncertain. It may reflect either minor ore-controlling factors or the "noise" from various errors.
Combined with Fig. 1, it has been shown by Fig. 4 that the Tongshi complex and all gold deposits are distributed at the saddle valley (with gravity anomaly values varying from -55 to $51 \mu \mathrm{m} \mathrm{s}^{-2}$ ) of the northwest trending concealed basement (with gravity anomaly values varying from 52 to $567 \mu \mathrm{m} \mathrm{s}^{-2}$ ) on the southwestern side of the Pingyi volcanic sedimentary basin (with gravity anomaly values varying from -56 to $974 \mu \mathrm{m} \mathrm{s}^{-2}$ ). The saddle valley may 
be tectonically an extensional area where it is easy for the Tongshi complex to emplace, and thus constitutes a regional ore-controlling factor for the gold mineralization in the Tongshi gold field. Figure 5 indicates the configurations both the Tongshi complex (with the negative gravity anomaly values varying from -339 to $-11 \mu \mathrm{ms}^{-2}$ ) and the ring contact metasomatic mineralization zone(with the positive gravity anomaly varying from 37 to $345 \mu \mathrm{m} \mathrm{s}^{-2}$ ) around the Tongshi complex. The Skarn and porphyry types of gold deposits are located within the complex pluton, and the Carlin and Crypto-breccia types of gold deposits are located within the contact metasomatic mineralization zone. The two areas are potential areas for gold deposits. In conclusion, the gold ore-mineralization in Tongshi gold field is controlled by multilayer ore-controlling factors, showing typical complexity of ore-controlling factors.

\section{Conclusions}

The multi-fractal singular value decomposition (SVD) could effectively separate a single layer of ore-controlling factor from complicated geological factors. Combined with the geological background of the Tongshi gold field, the regional and local ore-controlling factors could be extracted.

1. The regional ore-controlling factor is a saddle valley of the NW trending swell on the SW side of the Mesozoic volcanic sedimentary basin. The saddle valley might be tectonically an extensional area where the Tongshi complex pluton and all gold deposits are located and thus this area is a favorable area for gold deposits.

2. The local ore-controlling factor is the Tongshi complex pluton with a negative circular gravity anomaly and the ring contact metasomatic mineralization zone around the Tongshi complex with the positive gravity anomaly. The skarn and porphyry types of gold deposits are located within the complex pluton and the Carlin and Crypto-breccia types of gold deposits located within the contact metasomatic mineralization zone and thus the two areas are potential areas for gold deposits.

3. The Tongshi gold field has a typical complexity with multi-layers of ore-controlling factors.

Acknowledgements. We thank F. P. Agterberg and an anonymous reviewer for their critical review of the paper and constructive comments. This research was jointly funded by National Natural Science Foundation of China (grant Nos: 40972232, 40772197) and National High-Tech Research \& Development (No: 2006AA06Z113). We also thank Yanzhou Geology \& Mineral Exploration Institute of Shandong province for providing original gravity data for the research.
Edited by: A. G. Hunt

Reviewed by: F. Agterberg and another anonymous referee

\section{References}

Cagnoli, B. and Ulrych, T. J.: Singular value decomposition and wavy reflections in ground-penetrating radar images of base surge deposits, J. Appl. Geophys., 48, 175-182, 2001.

Chen, Y. Q., Xia, Q. L., and Liu, H. G.: Delineation of potential mineral resources region based on geo-anomaly unit, J. China Univ. Geosci., 11, 158-163, 2000.

Chen, Y. Q., Zhao, P. D., Chen, J. G., and Liu, J. P.: Application of the geo-anomaly unit concept in quantitative delineation and assessment of gold ore targets in western Shangdong uplift terrain, eastern China, Natural Resources Research, 10, 35-49, 2001a.

Chen, Y. Q., Zhao, P. D., and Liu, H. G.: Accumulation and evolution of ore-forming composition of gold deposits in the western Shandong uplift terrain, J. China Univ. Geosci., 26, 4148, 2001 b.

Cheng, Q. M.: Mapping singularities with stream sediment geochemical data for prediction of undiscovered mineral deposits in Gejiu, Yunnan Province, China, Ore Geol. Rev., 32, 314-324, 2007.

Cheng, Q. M.: Non-Linear Theory and Power-Law models for Information Integration and Mineral resources Quantitative Assessments, Math. Geosci., Special Issue, 503-532, 2008.

Cheng, Q. M., Zhao, P. D., Chen, J. G., Xia, Q. L., Chen, Z. J., Zhang, S. Y., Xu, D. Y., Xie, X. Y., and Wang, W. L.: Application of Singularity Theory in Prediction of Tin and Copper Mineral Deposits in Gejiu District, Yunnan, China: Weak Information Extraction and Mixing Information Decomposition, J. China Univ. Geosci., 34, 232-242, 2009.

Freire, S. L. M. and Ulrych, T. J.: Application of singular value decomposition to vertical seismic profiling, Geophysics, 53, 778-785, 1988.

Glifford, G. D.: Singular Value Decomposition Independent Component Analysis for Blind Source Separation, HST582J/6.555J/16.456J, Biomedical signal and Image Processing, 2005.

Hronsky, J. M. A. and Groves, D. I.: Science of targeting: definition, strategies, targeting and performance measurement, Aust. J. Earth Sci., 55, 3-12, 2008.

Hu, H. B., Mao, J. W., Niu, S. Y., Li, M. W., Chai, F. M., Li, Y. F., and Liu, T.: Study on ore-forming fluids of the Guilaizhuang gold deposits in Pingyi, Western Shangdong, Journal of Mineralogy and Petrology, 29, 38-44, 2005.

Li, Q. M.: GIS-based multifractal/inversion methods for feature extraction and applications in anomaly identification for mineral exploration, Ph.D. thesis, York University, Toronto, Canada, 211 pp., 2005.

Li, Q. M. and Cheng, Q. M.: Fractal Singular-Value (Eigen-Value) Decomposition Method for Geophysical and Geochemical Anomaly Reconstruction, J. China Univ. Geosci., 29, 109-118, 2004.

Li, Q. M. and Liu, S. H.: Geophysical signal decomposition by singular method and application in GIS, Progress in Geophysics, 18, 97-102, 2003. 
Lin, J. Q. and Tan, D. J.: ${ }^{40} \mathrm{Ar} /{ }^{39} \mathrm{Ar}$ Ages of Mesozoic Igneous Activities inWestern Shandong, Acta Petrologica et Mineralogica, 15, 213-220, 1996.

Pan, G. C. and Harries, D. P.: Information synthesis for mineral exploration, Oxford University Press, Unite Kingdom, 461 pp., 2000.

Turcotte, D. L.: Fractals and chaos in geology and geophysics, 2nd edn, Canbridge University Press, Cambridge, United Kingdom, 398pp., 1997.

Ulrych, T. J., Freire, S. L. M., and Siston, P.: Eigenimage Processing of Seismic Sections, in: S22 - Seismic sessions: signal-to-noise enhancement II, SEG Expanded Abstracts, 7, 1261, doi:10.1190/1.1892508, 1988.
Vrabie, V. D., Mars, J. I., and Lacoume, J. L.: Modified singular value decomposition by means of independent component analysis, Signal Process., 84, 645-652, 2004.

Wang, S. C., Liu, Y. Q., Yi, P. H., Zhang, Y. Q., Yang, Y. H., Yang, D. L., Huang, T. L., Fang, J. Z., Li, S. X., Dong, T., Chen, Y. Q., and Ye, S. S.: Gold deposits and the synthetic information metallogenic prognosis in gold deposit concentrated area, Geological Publishing House, Beijing, China, 2003

Yu, X. F.: Ore-forming Series and Model of Tongshi Gold Field in Pingyi, Shangdong Province, Shangdong Geology, 17(3-4), 59-64, 2001.

Zhu, D. P., Zhang, X. M., Li, S. Q., and Qi, K. K.: The mineralization types of Tongshi district of secondary volcanic complex rock mass in Pingyi County and their geological feature of mineralization, Gold, 21, 8-11, 2000. 